\title{
ON THE VERY IDEA \\ of Metalinguistic THEORIES OF NAMES
}

\author{
AIDAN GRAY \\ University of Illinois at Chicago
}

\begin{abstract}
Metalinguistic approaches to names hold that proper names are semantically associated with name-bearing properties. I argue that metalinguistic theorists owe us an account of the metaphysics of those properties. The unique structure of the debate about names gives an issue which might look to be narrowly linguistic an important metaphysical dimension. The only plausible account of name-bearing treats name-bearing properties as a species of response-dependent property. I outline how such an account should look, drawing on forms of response-dependence identified in the literature on colour, moral properties, etc. Having done that, I show how the account can illuminate a feature of the communicative function of names which would otherwise be puzzling from the perspective of metalinguistic accounts.
\end{abstract}

\section{Metalinguistic Approaches to Names}

There is more than one Alfred. So distinct occurrences of 'Alfred' can refer to distinct individuals. On one way of thinking about it this should be understood as a kind of homonymy: occurrences of 'Alfred' which refer to different individuals are articulations of different lexical items. Call this homonymism about names. Traditional philosophical approaches to names, which model names on individual constants, are homonymist.

An opposing approach treats names as univocal: the same lexical item can be used in reference to different individuals. This approach treats names as context-sensitive referring expressions. Such approaches are often variants of metalinguisticism about names, in that they hold that the name 'Alfred' is semantically associated with the property of bearing the name 'Alfred', and that the distribution

Contact: Aidan Gray <gray.aidand@gmail.com> 
of this property constrains the possibilities for reference with the name. ${ }^{1}$

The move from the rejection of homonymism to the acceptance of metalinguisticism is not unavoidable, but it has a certain naturalness. ${ }^{2}$ Once we have accepted that names are not referentially ambiguous, but rather referentially context-sensitive, it's natural to ask how the lexical meaning of a name differs from the lexical meaning of other context-sensitive referring expressions-for example, pronouns. Or to ask how the lexical meaning of two names-say 'Alfred' and 'Helen'-differ from each other. And the answer seems to be that what is characteristic of a particular name, as a lexical item, is the conditions it places on successful reference. 'Alfred' can be used, in the right context, to refer to any Alfred, 'Helen' to any Helen, etc. Thus, the assumption that names are univocal naturally leads to the thought that their context-invariant meaning should be characterized partly in terms of a corresponding name-bearing property (for a related line of thought, see Recanati 1997: 139). That property is what constrains the reference of a name in a context. This initial thought might be bolstered by finding inferential patterns which seem to rely on the presence of a semantic constraint of this kind (see, e.g., Burge 1973; Hornsby 1976; Schoubye 2016b).

Varieties of metalinguisticism differ with respect to their conception of the semantic-type of proper names. Predicativism holds that names are predicates in the lexicon. ${ }^{3}$ So, for example, 'Alfred' is a predicate true of all and only the Alfreds. Standard forms of Predicativism hold that when names appear in argument positions, in languages which allow that, they are accompanied by an unpronounced determiner. Varieties of Predicativism differ with respect to the nature of that determiner: it might be a demonstrative (Burge 1973), a definite determiner (Fara 2015: Matushansky 2008: Sloat 1969), or something else (Gray 2017b).

Metalinguistic referentialists hold that names are context-sensitive individualdenoting expressions. ${ }^{4}$ Varieties of metalinguistic referentialism differ with respect to how they understand the role that name-bearing properties play in restricting the reference of name-occurrences. On some approaches, name-bearing properties function to restrict the range of individuals which can occupy a contextual

1. In a sense, 'metalinguistic' is not a great term here, insofar as it might be taken to suggest that these views treat names as somehow quotative of other, more basic, expressions. This is clearly not what theorists have in mind. I stick with 'metalinguistic' to mark the fact that these theorists gloss the properties expressed by names in terms of linguistic idioms: being called, being given a name, being dubbed, etc.

2. For a picture of names which is both non-homonymous and non-metalinguistic, see Delgado (2016). For a view of names which is homonymous but still metalinguistic, see Garcia-Carpintero (in press).

3. See Sloat (1969), Burge 1973), Hornsby (1976), Katz (1990), Geurts (1997), Bach (2002), Elbourne (2005), Matushansky (2008), Sawyer (2009), Fara (2015).

4. See Recanati (1997. Chapters 8-9), Pelczar and Rainsbury (1998), Maier (2009), Rami 2014b), and Schoubye (2016b). 
parameter which determines the reference of a name (Pelczar \& Rainsbury 1998; Recanati 1997); on others, they function as a semantic presupposition on variable assignments (Schoubye 2016b); on others, they determine the 'use-conditions' of names (Rami 2014b).

This paper abstracts away from differences between these approaches. They share the assumption that names are univocal, and that name-bearing properties constrain the reference of name-occurrences. We will explore what one would have to think to hold that this approach is so much as coherent. Sections 2 and 3 introduce the central question for metalinguistic approaches: the nature of namebearing properties. Sections 4 and 5 introduce and defend a response-dependent account of name-bearing. Section 6 shows how the response-dependent account can illuminate a feature of the role that names play in communicative practice that would otherwise be puzzling from the point of view of metalinguisticism.

\section{An Unavoidable Entanglement with Metaphysics}

In this section, I'll argue that the debate between metalinguisticism and homonymism cannot be evaluated in the absence of an account of the nature of name-bearing properties. This distinguishes the debate from other controversies in syntax and semantics. It also conflicts with the assumptions of most metalinguistic theorists.

\subsection{The Standard Division of Labour}

It's not the job of semanticists to explain everything. Standard procedure nowadays has linguists and philosophers of language offering hypotheses about how the significance of complex expressions depends upon the significance of their parts in a rule-governed way. When it comes to basic expressions-lexical items-we find a division. There is a class of 'functional' vocabulary-logical operators, determiners, etc.-for which we can offer revealing logico-mathematical characterizations of their meaning. But once we reach the class of substantive vocabulary—nouns, adjectives, verbs—we are satisfied, qua semanticists, once we have specified the semantic type of the expressions and identified how they interact with the compositional system (Glanzberg 2014). We do not typically require, before we evaluate a proposal about the compositional behaviour of a basic expression, a substantive characterization of its meaning. Typically, in characterizing the meaning of a substantive expression, one simply uses that expression in the metalanguage, or provides a rough paraphrase in other terms (a paraphrase which is not supposed to be, in itself, particularly revealing).

To take an example, suppose someone offers the following account of the meaning of 'she': 


$$
\begin{aligned}
\llbracket \text { she }_{i} \rrbracket^{c, v, w} & =v(i), \text { if } v(i) \text { is a female } \\
& =\varnothing \text { if } v(i) \text { is not a female }
\end{aligned}
$$

There are various ways in which it would be appropriate to reject it. Perhaps it is inappropriate to treat gender features as built-in presuppositions on individualdenoting expressions; Heim and Kratzer (1998) treat them as distinct partial identity function, thus positing a different syntactic/compositional structure to pronouns. It would be unusual, though, to insist that the semantic proposal about pronouns is incomplete until we are offered a substantive account of femaleness. Despite the fact that femaleness plays a substantive role in the semantic proposalthe distribution of that property constrains the possible reference of occurrences of the pronouns-it would be bizarre to suppose that the plausibility of the proposal depends on an account of it. On the standard division of labour, compositional semantics can proceed more or less independently of lexical semantics, psychology, sociology, biology, metaphysics, or wherever we might need to turn to get a theory of the substantive properties appealed to in the course of doing compositional semantics.

Proponents of metalinguisticism have embraced this standard division of labour when it comes to names. Burge writes,

It is not incumbent on us (as truth theorists) to define the conditions under which proper names, or any other predicates, are true of objects. The vague necessary and sufficient application condition for proper names which I have offered may be regarded as a mere stand-in for a full-fledged empirical account of how objects get proper names attached to them. Baptism, inheritance, nicknaming, brand-naming, labeling may all be expected to enter into such an account. Semantics, however, need not await the full returns of sociology. Rules like the following are sufficient: 'O'Hara' is true of any object $y$ just in case $y$ is an $\mathrm{O}^{\prime} \mathrm{Hara}$. 1973: 435)

Metalinguistic theorists have tended to follow him in this nonchalance about name-bearing (see, e.g., Bach 2015: 777; Elbourne 2005: 212; Geurts 1997; 326). I will argue that this is inappropriate by identifying two disanalogies between the debate between competing accounts of pronouns and the debate between homonymism and metalinguisticism about names.

\subsection{The Structural Argument}

First, note that there is a structural difference between the case of pronouns with respect to gender and the case of names with respect to name-bearing. The choice between the relevant alternatives for pronouns is independent of theories of the 
nature of gender properties. No choice, within the relevant class of possibilities, about the syntax and semantics for pronouns commits one to anything about the nature of gender. But the situation is not so for the choice between homonymism and metalinguisticism; theories of the semantics of names are not independent of the nature of name-bearing properties.

To see this, consider name-bearing from the point of view of homonymism. From that point of view, what is fundamental are the particular referentiallyinvariant lexical items pronounced 'Alfred', and their referential relations. There is a metasemantic story which explains why a particular lexical item pronounced 'Alfred' refers to some individual. Given a class of such lexical items and their referents, we can characterize the property of being an Alfred by generalizing over those items: what Alfreds have in common is being the referent of a name pronounced 'Alfred'.

HOMONYMIST NAME-BEARING $x$ is an Alfred $\equiv$ there is a name $n$ pronounced 'Alfred' such that $x$ is the referent of $n$.

Thus homonymism involves a certain picture of the nature of name-bearing properties. They are metalinguistic generalizations over context-invariant referential lexical items. So the move to metalinguisticism will involve not simply a new picture of the semantics for names but also a new picture of the nature of namebearing properties. Metalinguisticism denies that there are such lexical items, so it cannot see name-bearing properties as generalizations over them. ${ }^{5}$ For metalinguisticism, there is one lexical item 'Alfred'. It is semantically associated with the property of bearing the name 'Alfred'. Individuals instantiate that property, and their instantiating it is not mediated by the semantic properties of some other expression. Metalinguistic theorists need to characterize what it is to be an Alfred in some way that doesn't involve appeal to a referentially-invariant term pronounced 'Alfred'.

So the choice between homonymism and metalinguisticism about names is unlike the choice between different accounts of pronouns. Metalinguisticism entails the negation of the homonymist account of name-bearing (and vice-versa). So the choice between metalinguisticism and homonymism is committal with respect to the nature of name-bearing in a way that the choice between competing theories of pronouns is not committal with respect to the nature of gender. So metalinguistic theorists are entangled in a metaphysical controversy, whether or not they want to be.

5. An exception to this is the sort of metalinguisticism proposed in Garcia-Carpintero (in press), which I won't discuss here. 


\subsection{Mutual Dependence}

It is not simply that metalinguistic approaches are committal with respect to the nature of name-bearing; they entail that name-bearing exhibits a puzzling form of mutual dependence with name-reference.

The sense in which, for a metalinguistic theorist, facts about name-reference depend on facts about name-bearing is obvious. That dependence is built into the approach. For the metalinguistic theorist, the semantics for a name determines that only individuals who posses the corresponding name-bearing property can be the referent of an occurrence of the name.

The other direction of dependence-the sense in which facts about namebearing depend on facts about name-reference-is less obvious, and is typically ignored by metalinguistic theorists. An individual can come to bear a name in virtue of the referential practices of groups of speakers. Consider, what from the point of view of homonymism are considered, cases of 'reference-transfer'. An individual is baptised with a name, thus instituting a practice of using that name to refer to the individual. The practice is passed from person to person along a communicative chain, with each successive speaker intending to refer to the same individual as the speaker from whom she learned the name. Somewhere along the way a speaker, or set of speakers, misidentify who the name refers to. Their utterances involving the name are guided by beliefs about a new object. If a stable practice of this kind develops-with utterances of the name being guided by speakers' attitudes about a different object-that object comes to be a bearer of the name.

The classic example in the philosophical literature is the case of Madagascar. Evans tells us that Madagascar acquired its name as the result of a confusion, on the part of European explorers, with a certain part of the African mainland which bore that name (1985: 11). Given that it was a confusion, the island's coming to bear that name involved no stipulation, agreement, or baptism. Some initial confusion brought about a stable practice on the part of some speakers to use 'Madagascar' when they intend to refer to the island and to take their cohorts' use of 'Madagascar' to indicate an intention to speak about the island.

From the point of view of metalinguisticism, cases of this kind reveal that facts about name-bearing depend on facts about name-reference. So we have modes of dependence running in both directions from name-reference and name-bearing. This is, at least, interesting. More worryingly, it might reveal that metalinguisticism is committed to a viciously circular form of explanation, a charge made famous in Kripke (1980: 68). This would be troubling.

An important caveat here: it might be thought that I have been sloppy in describing the case, and that it is this sloppiness that has generated the appearance 
of a troubling circularity. ${ }^{6}$ Perhaps what Madagascar-type cases show is only that facts about name-bearing depend on facts about speaker-reference. They do not show that facts about name-bearing depend on facts about the semantic reference of occurrences of names. After all, the practice which seems to make it the case that the island comes to bear the name is not a practice in which occurrences of 'Madagascar' semantically refer to the island (by the metalinguistic theorist's lights, the occurrences cannot semantically refer to the island before the island bears the name). It is a practice in which individuals make speaker-reference to the island by deploying the name (depending on one's theory, these occurrences either fail of semantic reference or will refer to the relevant part of the mainland).

As it happens, I think this is more or less correct. The account of name-bearing which I offer below is fundamentally an exploration of this idea. But, as we will see, taking this tack does not remove the threat of vicious circularity; it merely relocates it. (In my view, it relocates it to a more manageable area, but we will see that this isn't obvious.) To get a preliminary sense of this, note that on a plausible account of speaker-reference, a speaker refers to $o$ in using a name $N$ only if the speaker presupposes that $o$ bears $N$. Thus, treating name-bearing facts as dependent on facts about speaker-reference would make name-bearing facts dependent on facts about speakers attitudes about name-bearing facts. And this is not obviously innocent.

So metalinguistic theorists are not-pace Burge-awaiting the returns of sociology to reveal the nature of name-bearing. They are also awaiting the returns of philosophy. And one of the possible outcomes of the philosophical investigation is that metalinguistic approaches are committed to an incoherent form of explanation. Nonchalance is not the appropriate attitude here. Note that we don't see the same form of mutual dependence in the homonymist picture. Name-bearing properties are epiphenomenal in the homonymist picture. For homonymists, being an Alfred is no more theoretically relevant to name-reference than having a name that starts with an ' $A$ ', or having a name that rhymes with 'shoe'. 7 Metalinguistic theorists need to reassure us that the price of their semantic theory isn't metaphysical confusion.

\section{A Brief Tour of Unpromising Approaches}

Metalinguistic theorists are not completely silent about the nature of name-bearing properties. Some outline the sort of account they want to go in for. Space prevents a serious discussion of possible alternatives to the approach I develop below. But

6. Thanks to an editor at Ergo for raising this issue.

7. Here I ignore Kaplan (1990) on 'generic names'; though even if we take 'generic names' to be relevant to theorizing about names in the homonymist paradigm, they do not constrain name-reference. 
we'll work our way towards the favoured approach by identifying challenges for the alternatives. I'll give caricatured versions of the alternatives here, designed to highlight their flaws. The actual approaches are more subtle. But to the extent that they can avoid the challenges outlined, I suspect they will converge on the response-dependent approach I defend below.

\subsection{The Dubbing Approach}

One sort of picture of name-bearing one finds in the literature sees the distribution of name-bearing properties as determined by the history of events in which speakers assign names to individuals by employing conventionally-sanctioned ceremonies or procedures. Burge holds that a name is a predicate true of individuals who have been "given the name ... in a socially appropriate way" (1973: 428-429). Geurts suggests that one can acquire a name by any of a variety of different socially conditioned "naming practices", such as baptisms, birth-certificates, etc. 1997. 327). Pelczar and Rainsbury appeal to the idea of a 'dubbing', which is "a speech-act whereby a name acquires a referent" (1998, 294).

The details of the dubbing approach could be elaborated in different ways. The essential idea here is that name-bearing properties are essentially historical. Their distribution is constituted by dated events of name-stipulation. But cases of 'reference-transfer' are a fundamental stumbling block. As the case of Madagascar shows, an individual can come to bear a name in the absence of any event of bestowing the name upon the individual. Proponents of the approach might be tempted, at this point, to posit 'implicit' dubbings to capture these cases. But this is just a way of abandoning the approach without admitting that you are abandoning it. Cashing out the idea of an implicit dubbing would involve recapitulating the response-dependent account I outline below. The dubbing conception of name-bearing properties fails to capture the dependence of namebearing on name-reference.

\subsection{The Practice Approach}

Another picture of name-bearing sees the distribution of name-bearing properties as determined by practices of using a name to refer to an individual. For example, Loar writes, " $N$ is the name of $x$ in a group $G$ just in case it is mutual knowledge among the members of $G$ that it is their practice to (or they have agreed that they may) utter $N$ and thereby refer to $x$ as being called $N^{\prime \prime}$ (1976: 160; see also Loar 1980, Recanati 1997. Sections 8.3, 9.3).

Ignore, for now, the parenthetical. Focus on the idea that for an object to bear a name there must be practice of using the name to refer to it. It looks like the practice approach stumbles at the place where the dubbing approach succeeds. An individual, $o$, can come to bear the name $N$ via an act of stipulation. Thus there 
can be name-bearing without a practice of name-reference. If, after a stipulation, a speaker uses $N$ to refer to $o$, she doesn't thereby make it the case that $o$ bears the name $N$. She can use $N$ to refer to $o$ because o bears $N$. This is clearly why the parenthetical is inserted in Loar's characterization. We might worry about the disjunctive nature of the characterization, or balk at the idea that baptism is a kind of agreement. But leave that aside.

It initially seems as though the practice approach does a better job with 'reference-transfer'. Thinking of Madagascar, we said that the island came to bear the name 'Madagascar' in virtue of the practice on the part of Europeans of using 'Madagascar' to refer to it. That's fine as far as it goes. But the details are elusive. When, exactly, did the island come to bear the name? On the first occasion on which a European used 'Madagascar' in an attempt to speak about it? Surely not. A single mistake is not enough. We're inclined to say that island came to bear the name once the practice became 'established', or 'systematic', or whatever. The challenge is to give content to those approbations.

Triangulating on these two problems, we can see that if the practice approach is to work we must develop a notion of 'practice' which characterizes a kind of normative potential for reference, rather than a kind of actual pattern of (attempted?) reference. I don't deny that this is likely what practice-theorists have in mind (see Loar's talk of 'mutual knowledge'). But the trick is making it work. Again, my guess is that capturing these desiderata will transform a practice account into the kind of response-dependent account I outline below.

\section{Name-Bearing as Response-Dependent}

Metalinguistic theorists should treat name-bearing properties as members of a class of philosophically well-studied (though controversial for all that) properties: response-dependent properties. The response-dependent account of name-bearing properties will represent them as no more or less mysterious than other responsedependent properties. This is not unequivocally good news for metalinguistic theories. Accusations of incoherence have long followed response-dependent accounts, or at least a certain class of them. And we will see below that a response-dependent account of name-bearing has certain puzzling features.

In this section I will introduce the idea of response-dependence and develop a response-dependent account of name-bearing by locating it with respect to some established choice-points in theorizing about response dependence. In Section 5. I will confront the possibility that a response-dependent account of names is viciously circular. 


\subsection{Response-Dependence}

At a broad level, response-dependent properties are properties whose distribution is grounded in relations between objects and 'human subjectivity'. At a slightly narrower level, an object bears a response-dependent property in virtue of being such as to elicit, or otherwise be the object of, a mental response from an agent, or agents, under certain specified conditions. ${ }^{8}$ A range of quite different properties have been taken to be response-dependent. Sensory properties-colours, smells, tastes, etc.- - are a central example. There are also response-dependent analyses of other philosophically central properties like values (both moral and aesthetic) or meanings. It is often noted in passing that other ordinary properties - like being nauseating, being humorous, being polite, being cool (in the sense of hip, not in the sense of cold)_-are response-dependent properties.

Once we leave the safety of platitudes, and try to pin down a precise responsedependent account of a given property, a range of subtle choices faces us. The starting point for response-dependent ('R-D' hereafter) accounts is a biconditional of the form specified in (R-D BICONDITIONAL). ${ }^{9}$

R-D BICONDITIONAL $x$ is $F \equiv x$ stands in relation $R$ to mental state $M$ of subject(s) $S$ in condition $C$.

R-D biconditionals claim an equivalence between being $F$ and standing in some relation to some mental state of some subjects under some conditions. We get an instance of the R-D biconditional by filling in the blanks. To give an example, the R-D biconditional for redness will look something like (RED).

RED $x$ is red $\equiv x$ looks red to normal perceivers in normal conditions.

As we shall shortly see, there a number of issues interpreting the theoretical import of this kind of equivalence. But one thing it is supposed to capture is the fact that if red is response-dependent, then "a certain kind of scepticism" about which things are red is "incoherent" (McGinn 1983: 12). There is some sense in which the facts about which things are red cannot systematically diverge from which things we 'take' to be red. ${ }^{10}$ Certainly, local error is possible. But the thought

8. The term 'response-dependence' is due to Johnston (1993). Different terms are used for roughly the same idea. The historical term was 'secondary-qualities', and this is still used in connection with perceptible properties. As I mention below, related ideas-and sometimes the same terms-are used to characterize concepts instead of properties. Wright's (1988) notion of extension-determining concepts is in this family.

9. Here I follow the general trend. I'm inclined, though, to agree with Wedgwood (1998) and García-Carpintero (2007) that the notion of response-dependence should be understood more broadly than this kind of dispositionalist implementation.

10. Two caveats here: First, I use the vague notion 'take' on purpose. If the extensiondetermining response is not judgment-or appropriately connected to judgment-it might be 
that objects systematically do not have the colour that they appear to have is in conflict with (RED). We can see an initial motivation for treating name-bearing as response-dependent by noting an equivalent feature. Though local error is certainly possible-individuals or groups can be wrong for various reasons about who bears what name-name-bearing properties cannot systematically diverge from speakers' take on them. This is an upshot of Madagascar-cases.

\subsection{Property or Concept?}

A high-level choice point in developing R-D approaches concerns the putative significance of R-D biconditionals. Do we take the biconditional, in the first instance, to tell us something about a concept or about a property? Typically, if we take it to be characterizing a concept, we will claim that the biconditional is known a priori by agents who posses the concept; if we take it to be characterizing a property, we will claim that it is a necessary truth about the property. ${ }^{11}$

Relative to each of these options, more choices emerge. If the biconditional characterizes competence with a concept how does it do so? Is the defined concept composed of the defining ones? Or does the definition merely characterize the kind of evidence that an agent who is competent with concept must be sensitive to (Peacocke 1992: Pettit 1991)? If the biconditional characterizes a necessary truth about a property, does it do anything more than that? Does the necessary truth underwrite a claim of property identity between the two sides (McGinn|1983)? Does it characterize something about the nature of the property (García-Carpintero 2007; McDowell 1985: Wedgwood 1998)? Does it characterize the supervenience base of the property (McGinn 1996)?

With respect to name-bearing, we will focus on properties. Recall that our topic here is the choice between metalinguisticism and homonymism. The two approaches entail different approaches to the nature of name-bearing properties but do not, without further assumptions, entail anything about concepts. So the relevant action is at the level of properties (though, we will see shortly that metalinguisticism does have to invoke concepts at a crucial moment). I'll remain neutral about the relation between necessary equivalence and property identity.

possible to be systematically mistaken in our judgments about which objects bear a responsedependent property. As Holton (1991: Section II) points out, we might be systematically wrong about which objects are nauseating because we are systematically wrong about which objects cause nausea. Still, it is not possible for the facts about what is nauseating to systematically diverge from our nausea-responses. Second, 'systematically' is doing a lot of work here. Some R-D accounts appeal to ideal conditions rather than normal conditions. And relative to such accounts, it would be possible to hold that the facts about the distribution of an R-D property are radically different than we take them to be because we are rarely, or perhaps never, in ideal conditions. Thanks to Dave Hilbert for pointing this out.

11. There are, of course, connections between these ways of thinking about responsedependence. See Wedgwood (1998), Brynjarsdóttir 2008), Sveinsdóttir 2008), Howat (2011). 
We will hope to find a necessary biconditional linking name-bearing properties and responses which reveals enough about the nature of name-bearing to defuse the worry that metalinguisticism is metaphysically incoherent.

\subsection{What Response?}

In specifying the response which is relevant for giving an R-D account of namebearing, we have a wide range of precedent to choose from. In R-D accounts of colour, we find appeals to an object's looking green (McGinn 1983) or causing a red sensation (Peacocke 1984; 1992). In Lewis's (1989) R-D account of value, we find appealing to object's being desired. In some discussions, we simply find appeal to judgments about objects (Holton 1991; Johnston 1993: 105). To give a flavour of the variety here, I present some examples (note that not all of these accounts are endorsed by the authors).

$x$ is a value $\equiv$ we are disposed to desire having a desire for $x$ under conditions of imaginative acquaintance with $x$ (see Lewis 1989)

$X^{\prime}$ s cause $Y^{\prime} s \equiv$ under conditions in which we wanted to bring about $Y^{\prime}$ s and in which our abilities were not subject to the various sorts of contingent limitations from which we suffer we would be disposed to manipulate $X^{\prime}$ 's as a means of bringing about $Y^{\prime}$ 's (Johnston 1993. 105)

$A$ is an act for which $S$ is responsible $\equiv$ we are disposed to hold $S$ responsible for $A$ (Johnston 1993: 105)

We should mark a distinction which is typically made: reductive vs. non-reductive R-D biconditionals. When giving an R-D account of a property, should we appeal to a response which is characterized in terms of that very property? Take redness again; an R-D account posits a necessary equivalence between an object's being red and its looking a certain way under certain conditions. What way? One tempting answer is: looking red. We might characterize the response in terms of the property we are claiming to be response-dependent. Call this, following Byrne and Hilbert (2011), a non-reductive R-D account. ${ }^{12}$

Alternatively we might characterize the responses in other terms. For example, Peacocke characterizes the response-dependent property of being a red object in terms of the sensational property of being a red' region of the visual field. Here $\mathrm{red}^{\prime}$ is taken as relatively more fundamental, not ultimately to be explained in terms of red. So the red biconditional looks something like $\left(\mathrm{RED}_{1}\right)$.

12. Holton (1991) calls these, in the context of his discussion of response-dependent concepts, echoic concepts. Watkins (1994) calls the non-reductive approach the "frugal" approach; the reductive approach is called "extravagant". 
$\mathbf{R E D}_{1} x$ is red $\equiv x$ is disposed in normal circumstances to cause the region of the visual field in which it it presented to be red' in normal humans. (Peacocke 1984; 375; 1992: 37)

Given certain explanatory projects (e.g., definition, analysis, etc.), we would have no choice but to aim for a reductive biconditional. But given more modest aims, we might be satisfied with a non-reductive biconditional. Or we might not (see Blackburn 1993 261). We will bracket it for now, and address it head on in Section 5 .

Speaking generally, we will be driven to give a non-reductive R-D account of a property, and face the concomitant worries about circularity, if we are convinced that a property is response-dependent-because we don't see how its nature and distribution could be otherwise than essentially connected to human responsesbut cannot characterize the extension-determining response otherwise than with property in question. This is a theme of McDowell's $(1985 ; 1987)$ work on the secondary-quality conception of values. But he makes the same point with less philosophically freighted examples. Take, for example, the comic or funny. It seems clear that what is comic or funny is determined by human responses. But if we ask what response determines which things are funny, it's difficult find a response which we can characterize in terms which don't presuppose the comic or funny and which is extensionally correct. To take an obvious example, laughter won't do the trick; we laugh at awkward situations as well as funny ones (McDowell 1987; 6). So perhaps we must characterize the response in terms of funny, or in terms of some property in the same family (like amusement).

The distinction between reductive and non-reductive R-D biconditionals is not always straightforward to deploy. Deploying it depends on having an antecedent view about which properties are relatively more fundamental. In the case of name-bearing, it is tempting to posit an R-D biconditional which characterizes the distribution of a name-bearing property in terms of attitudes about the corresponding name - that is, in terms of the expression 'Alfred', rather than the property of being an Alfred. ${ }^{13}$ Perhaps we could give a reductive R-D biconditional which fleshes out the structure in $\left(\mathrm{ALFRED}_{1}\right)$.

ALFRED $_{1} \mathrm{x}$ is an Alfred $\equiv x$ stands in $R$ to 'Alfred' for $S$ in $C$.

Would this be reductive or non-reductive? This depends on whether we take an expression to be relatively more fundamental than its meaning. Recall that for the metalinguistic theorist, the meaning of 'Alfred' involves the property of being an Alfred. So an appeal to the expression is a covert appeal to the property. So it is unlike Peacocke's appeal to red' and more like McDowell's appeal to amusement.

But before moving on, we should consider the possibility of an unambiguously reductive R-D account of name-bearing. Some metalinguistic theorists proceed

13. This is the approach in Gray (2014). I now take it to be, at best, misleading.

Ergo • vol. 5, no. o9 2018 
as if one might understand name-bearing in terms of relations between speakers and signs - that is, phonological/orthographic features rather than expressions (Matushansky 2006 288). ${ }^{14}$ So we might hope that we could generate an R-D biconditional by appealing to speakers' attitudes or dispositions with respect to signs, as in $\left(\mathrm{ALFRED}_{2}\right)$.

ALFRED $_{2} \mathrm{x}$ is an Alfred $\equiv x$ stands in $R$ to $\langle/$ 'alfrid $/, a \frown l \neg f \frown r e-d\rangle$ for $S$ in $C$.

This is clearly reductive. Facts about the orthographic/phonological type $<$ /'alfrid/, $a \frown l \frown f \frown r \frown e \frown d>$ are not grounded in facts about name-bearing, or in facts about the expression 'Alfred'. But it doesn't seem likely that any approach of this kind will work.

For the sake of having a concrete proposal to work with, consider (ALFRED 3 ).

ALFRED $_{3} \mathrm{x}$ is an Alfred $\equiv$ there is an expression $e$ pronounced $</$ 'alfrid/, $a \frown l \frown f \frown r \frown e \frown d>$ and speakers take it as appropriate to use $e$ to refer to $x$.

At first glance, this has some of the features we would want in an R-D account of name-bearing. It captures the normative potential that we saw was missing from the dubbing and practice approaches. But it is on the wrong track. It will count individuals as bearing the name 'Alfred' which shouldn't count as such.

To see this, note that there could be some other expression, not a name, pronounced the same way that the name 'Alfred' is pronounced which makes the right-hand side of $\left(\mathrm{ALFRED}_{3}\right)$ true. It is not uncommon for names to be articulated in the same way as some other kind of expression. As an example, there is both a name and a common noun spelled $k^{\frown} i^{\frown} n \frown g$. But an individual does not bear the name 'King' in virtue of it being deemed appropriate to refer him with the common noun 'King'.

We could imagine trying to refine the approach to rule out cases of this kind. It would be impossible to show that no reductive approach will work. But the prospects are not good. ${ }^{15}$ The distribution of name-bearing properties is

14. For another worry about this approach, see Gray (2015).

15. Essentially, the issue here is whether we can give a reductive condition on the righthand side which uniquely picks out the name in question. This really has two parts: $i$ ) giving a condition which ensures that we are identifying a name rather than some other kind of expression, and ii) giving a condition which insures that we are identifying a unique name. With respect to the first question, we might think that we could give a purely syntactic characterization of what it is for an expression to be a name. If that were the case, then we could screen off some of the unwanted entailments of $\left(\mathrm{ALFRED}_{3}\right)$ without going nonreductive. I'm sceptical that a purely syntactic criterion for namehood will be forthcoming (especially one that is cross-linguistically extensionally adequate). But it is worth noting the possibility here. With respect to the second question, I don't see any way that a purely syntactic 
determined by speakers' attitudes and dispositions with respect to names. And names, for the metalinguistic theorist, are constitutively connected to namebearing properties. I suspect there is no way for the metalinguistic theorist to get around that. It might be dialectically better for metalinguisticism if a reductive R-D approach were available. That would allow metalinguistic theorists to avoid delicate questions about circularity. But it seems that this is not the case. (See Wedgwood 1998 for a discussion of how a non-reductive approach is consistent with holding that an R-D characterization specifies the essence of the characterized property.)

In figuring out what kind of response is extension-determining for namebearing we have two fixed points from which to navigate. Cases of baptism show that an object can bear a name without ever having been referred to with it. Cases of reference-transfer show that an object can come to bear a name when a group of speakers' willingness to use the name in reference achieves a level of stability or structure. Triangulating from these two points above we said that name-bearing is a normative potential for reference.

So we are looking for a mental state linking an object, a name, and its corresponding name-bearing property, which makes it the case that the object is a potential referent of an occurrence of a name when the state, object, and property stand in the appropriate relation. In the context of metalinguistic approaches to names, the relevant state is presupposition. Presupposition-in the sense of Stalnaker 1974 b; $1978 \mathrm{a}$ ) - is a propositional attitude. A speaker who presupposes that $P$ in a conversation represents $P$ as taken for granted by participants in the conversation. The class of propositions a speaker presupposes is the information against the background of which a speaker forms communicative intentions and the hearer forms communicative beliefs. For metalinguistic theorists, names are definite noun phrases and, as such, a speaker who uses a name presupposes that the referent of that use satisfies the descriptive condition associated with the name. In a context, a name is suited to reference to an individual only if speakers in that context presuppose that the individual bears the corresponding name-bearing property. ${ }^{16}$ In a community, a name is generally suited to reference to an individual only if speakers are disposed in arbitrary contexts to presuppose that the individual bears the corresponding name-bearing property.

description could uniquely pick out a particular name. Note that nothing we have so far said entails that, from the point of view of metalinguisticism, two distinct names cannot share their phonology and orthography. See Section 5.4 below for a discussion. Such names would be distinguished, presumably, by their semantics. And appealing to their semantics would be to offer a non-reductive account. Thanks to an editor at Ergo for helpful discussion here.

16. Note that this presupposition is necessary but not sufficient to make a name suited to reference to an individual in a context. The target individual must also be identifiable as a bearer of the relevant name in the context. This identifiability constraint is a general feature of definite noun phrases. 
Metalinguistic theorists should treat presuppositions as the responses which are extension-determining with respect to name-bearing. Objects bear namebearing properties in virtue of speakers' dispositions to form presuppositions of a certain kind about those objects. The frame for an account of this kind is $\left(\mathrm{ALFRED}_{4}\right)$.

ALFRED $_{4} x$ is an Alfred $\equiv S$ is disposed to presuppose that $x$ is an Alfred in condition $C$.

It's not possible, of course, to fully justify this choice before filling in the rest of the details. But it will be instructive at this stage to compare this outline to other possibilities. In particular, we said a moment ago that presuppositions are the mental states which mediate between communicative intentions and the use of names in reference. But surely presuppositions are not the only such state. In normal contexts, speakers presuppose some subset of what they believe and so in the normal case, part of the explanation of why a speaker is in a position to use $N$ to refer to $o$ is that she believes $o$ bears $N$. So why not treat beliefs as the relevant responses in the case of name-bearing? It is not unusual, in the response-dependence literature, to see R-D biconditional stated in terms of belief or judgment. So this possibility cannot be dismissed.

First a preliminary point: given our focus is on properties, what we are looking for is a non-trivial necessary truth that links name-bearing with the responses of some agents under some conditions. There is no reason to believe that if there is such a truth, there will be only one. One of the consequences of not treating the R-D biconditional as, say, characterizing the structure of a concept is that there is no assumption of uniqueness. It might be that there are a variety of nontrivial necessary truths linking name-bearing and responses. Though our goal is imprecise, what we want is a picture of the response-dependent nature of namebearing which would satisfy us that the metalinguistic approach is metaphysically coherent. So we needn't necessarily resist alternatives. ${ }^{17}$

Having said that, I'm sceptical that a belief-version of the R-D biconditional would work. Simply put, when it comes to names what matters is what you are prepared to do, not what you believe. Imagine a group of speakers who used names just as we do: they presuppose of different individuals that they bear different names and they deploy those presuppositions in the use of names to refer to the relevant individuals. Suppose, though, that they also had strange beliefs about the nature of names. Perhaps they believe that only God can truly give a name to a person. They are willing to act, for the same of communication,

17. This is an oversimplification. On, for example, Wedgwood's (1998) approach, we are looking for a specification of the essence of an R-D property. This is, presumably, unique. If we took this approach to response-dependence we would have to choose between competitors. I'm sympathetic to Wedgwood's approach, but I won't assume it here.

Ergo • vol. 5, no. $09 \cdot 2018$ 
as if individuals bore certain names. But in their hearts they take themselves, and their peers, to be ignorant of the true names that God has distributed over individuals.

In principle, we could describe the case in two different ways. The individuals in this community do not have names, but speakers act as if they do. Or the individuals do have names, but the speakers have false beliefs about the nature of name-bearing, and the distribution of names. ${ }^{18}$ It strikes me that the second description is more natural. It would, for example, avoid the consequence that the utterances of this group systematically suffer from presupposition failure. In general, we don't want the semantic properties of utterances to be held hostage to whatever strange theories a group of speakers manages to cook up about linguistic matters.

So we'll stick with presupposition. Before we try to fill in the blanks of $\left(\mathrm{ALFRED}_{4}\right)$, we must address a significant complication. The proposal on the table here is that the distribution of name-bearing cannot systematically diverge from what speakers presuppose about that distribution (under certain, as yet unspecified, conditions). But we need to be more precise here. There are different guises under which speakers can presuppose that an individual bears a name. Suppose that the name 'Alvin' is my friend Helen's favourite name but I don't know this (I don't know which name is Helen's favourite name). Suppose further that I am told (falsely) that Alfred, with whom I am familiar but whose name I do not know, has Helen's favourite name. If I find myself in a group of friends in the same situation, we might presuppose that Alfred bears Helen's favourite name. Is there any temptation, here to conclude that Alfred therefore is an Alvin? Presumably not. But this is a situation in which speakers presuppose that Alfred bears the name 'Alvin'. ${ }^{19}$

The trouble here is that though the speakers presuppose that Alfred has the property being an Alvin, they don't think about the property in the right way. They don't think about it in a way that would move them to use the name 'Alvin' to refer to Alfred. So an R-D account of name-bearing must restrict the way that the property appears in the attitudes of speakers (see related discussion in Holton 1991: 5-6). Put vaguely, speakers must presuppose that an individual

18. It's important not to imagine the case in a way that we are tempted to say that they really do believe that the relevant individuals bear the relevant names but only implicitly, or in some other way that they wouldn't avow. Imagine, then, that when it comes to behaviour unrelated to the use of names in reference, they behave exactly as if they didn't believe that individuals bore the names they used to refer to them. For example, if you offered them a bet on the relevant propositions, they wouldn't take it.

19. To avoid getting hung up about de re/de dicto issues here, we can suppose that the speakers introduce some de re way of thinking about the property on the basis of the description. Perhaps they introduce a descriptive name for it. 
bears a name-bearing property $P$ by deploying a concept ${ }^{20}$ of that property which is suitably connected to the name which has $P$ as part of its meaning. Though I don't have a theory of what this 'suitable connection' amounts to, we should insist on the minimal condition that they must think of the property in a way that guides their use of the corresponding name. I'll say a little more about it in Section 5.4. The amended R-D biconditional will look like (ALFRED 5$)$.

ALFRED $_{5} x$ is an Alfred $\equiv S$ is disposed to presuppose (by deploying a concept suitably connected to the name 'Alfred') that $x$ is an Alfred in condition $C$.

This a general problem for R-D accounts which appeal to contentful mental states. We will always need a way of screening off attitudes which have the right content but the wrong mode of presentation. So the problem is not unique to an R-D account of name-bearing.

\subsection{Whose Responses? What Conditions?}

Supposing that presuppositions are the right attitude to focus on, we need to specify whose responses, under what conditions, determine the distribution of name-bearing properties. The question has a number of dimensions.

One issue here is the modal profile of R-D properties. One worry you might have about an R-D account of, for example, colour is that it would entail that if our perceptual systems had been different, objects would have had different colours (because they would have caused different perceptual experiences). This result offends against our ordinary notion of colour. Many theorists have noted that to avoid this unwanted result we need only actualize the right-hand side of the R-D biconditional with respect to subjects' perceptual system. ${ }^{21}$ There is some subtlety involved in getting the details right. But we can ignore that because name-bearing properties do not have an analogous modal profile. In possibilities where speakers are disposed differently with respect to the referential potential of names, objects would have different names (compare: if we had different practices, different actions would be polite). So we shouldn't actualize the right-hand side of the name-bearing R-D biconditional. ${ }^{22}$

20. I don't mean to be appealing to any substantive sense of 'concept' here. We can treat talk of concepts as a stand-in for whatever the correct story is about what explains the cognitive difference between attitudes which have the same referential content. The point here just is that we must restrict the 'way' that speakers think about name-bearing properties in the context of extension-determining presuppositions to ways that stand in the right cognitive connection to names-qua-expressions.

21. For discussion, see Wright 1989 . Footnote 27), Johnston 1989 141; 1992 230, 243), Lewis (1997 327), Lebar 2005).

22. Note that the non-rigidity of name-bearing properties has important consequences for 
Another issue in specifying the subjects whose responses are determinative with respect to the distribution of R-D properties is variation within actual subjects. The fact that there is variation across 'normal subjects' in judgments about colour is a challenge for R-D accounts of colour (Johnston 1992; Watkins 1994; 56). One response to this variation is to admit that $\mathrm{R}-\mathrm{D}$ accounts of colour entail relativism about colour (Johnston 1992, 247; McGinn 1983: 9). We might say that an object is red for a group of agents if and only if it looks red to them under normal conditions. Lewis concedes an analogous point about an R-D account of value (1989: 116ff.). This may or may not be a mark against an R-D approach of colour or value. ${ }^{23}$

Different speakers will presuppose different things about the distribution of name-bearing properties. So an R-D account of name-bearing could follow colours and values towards relativism. But there is an option for name-bearing which isn't plausible for colours or values: we could maintain absolutism about name-bearing by existentially generalizing over speakers, as in $\left(\mathrm{ALFRED}_{6}\right)$.

ALFRED $_{6} x$ is an Alfred $\equiv$ there is a group of speakers $G$ such that members of $G$ are disposed to presuppose (by deploying a concept suitably connected to the name 'Alfred') that $x$ is an Alfred in condition $C$.

We will shortly see why $\left(\mathrm{ALFRED}_{6}\right)$ generalizes over groups of speakers rather than individual speakers. For now we can note why this way of securing absolutism would not be appropriate for colours or values. It would not suit Lewis's purposes to treat values as absolute in this way because it would break the connection between the judgment that something is a value and the motivation to pursue it. If values were absolute in this way the judgment that $x$ was a value would have no special connection to pursuing $x$ because something might be a value in virtue of someone else's dispositions to desire. Lewis wants to secure a connection of that kind 1989 . 117). This form of absolutism would also be inappropriate for colours because it would fail to secure the incompatibility of colours (Watkins 1994 77). The same object might be red and blue in virtue of looking different ways to different people. This is thought to offend against truisms about colour.

But neither of these results is inappropriate for name-bearing. Name-bearing properties are not incompatible: there is nothing inconsistent about being, say, both a Peter and a Carl. And the judgment that an individual bears a name is not directly connected to speech behaviour. If one believes that $x$ is an Alfred,

the form of metalinguistic theories. Bare occurrences of names are rigid, so metalinguistic theorists must explain why the non-rigidity of name-bearing properties doesn't entail the non-rigidity of bare occurrences. For discussion, see Bach (2002), Elbourne (2005), Gray (2012), Fara (2015), Rami (2014a), Schoubye 2016a: 2016b), Gray (2017a).

23. On the other hand, it may be a virtue of R-D accounts of colour. If we have independent reason to think that some form of relativism is true of colours, then it will be a virtue of R-D accounts that they can capture the relativity of colours (Cohen 2009 Chapter 2). 
one is not thereby disposed to presuppose that he is come what may, but only in contexts involving other speakers who are likely to do the same.

So we're free to be absolutists about name-bearing and this seems to fit better with the truisms about name-bearing (see Gray 2017b. Section 3.2; Hornsby 1976. 231; Sawyer 2009).

How should we think of 'normal' or 'ideal' conditions for name-responses? Here the analogy with secondary qualities gets in the way. Colour-responses are wrung from agents on the basis of the interaction between their perceptual system, the local context, and the intrinsic properties of seen objects. The challenge for $\mathrm{R}-\mathrm{D}$ views of colour is to characterize the conditions under which the responses so wrung are to be treated as canonical. Name-responses are not like that. It is better to look for an analogy with R-D properties like being a polite action or being a cool dude. The responses which determine the distribution of these properties are not wrung from agents, and do not substantially depend on the intrinsic properties of objects. They function to coordinate certain kinds of behaviour in groups. There is no 'ideal' or 'normal' conditions for confrontation with a polite action. Individual politeness-responses are extension-determining when they are part of a coordinated group of politeness-responses, not when they are elicited during a particularly intimate confrontation with the objects of those responses.

We should say the same thing about name-bearing properties. Speakers coordinate their name-responses in order to facilitate communication about objects. An individual bears a name just in case a group of speakers have coordinated their speech behaviour around the presupposition that it does (compare: an action is polite just in case a group of social agents has coordinated their politenessbehaviours around the belief that it is). There are two related dimensions to the way that name-bearing, politeness, etc., differ qua response-dependent properties from secondary qualities. First, their extensions are not determined by individuals' isolated responses but rather by the structured responses of groups. Second, the extension-determining responses are not wrung from agents on the basis of the intrinsic properties of objects; agents coordinate them to play a role in some joint project. $^{24}$

So to fill in the details of the R-D biconditional for names, we need to figure out when a group has coordinated their presuppositions about an object's name in a way that makes it the case that the object bears a name. We can make progress here by thinking about of the structure of Madagascar-type cases. In these, what is initially a mistake on the part of some speakers about whether an object bears a name results in the object coming to bear the name. So we need a conception of

24. It's an interesting question what social function the coordination of politeness-reponses serves. I suspect there are different, related functions, and perhaps different functions dominate at different times. Hume apparently thought that the function of politeness was to conceal our pride (Tolonen 2008, 27). 
how a mistake turns into a practice; above we appealed to the vague idea of the systematicity or stability of a practice. In general, we can say that a practice which is born out of a mistake has become stable when the mistake no longer plays an essential role in sustaining that practice. In the case of Madagascar, the Europeans first began to presuppose the island bore the name 'Madagascar' because they falsely believed that Africans did the same thing. There was, presumably, some initial period of time in which discovery of this mistake would have meant that the Europeans would have ceased to presuppose that the island bore the name 'Madagascar'. At a later time, discovery of that mistake did not have the same effect. At some point, the fact that the Europeans themselves presupposed that the island bore the name was enough to sustain the practice.

This is a familiar point from the R-D literature. Extension-determining responses cannot be grounded in certain forms of error (see, for example, the list of errors mentioned in Wright 1988 18, in his discussion of colours). These sorts of restrictions do not trivialize an R-D biconditional so long as the absence of the relevant form of error is logically consistent with the relevant object failing to bear the relevant property (see Section 5.2).

Incorporating this into the R-D biconditional for names, we get $\left(\mathrm{ALFRED}_{7}\right)$.

ALFRED $_{7} x$ is an Alfred $\equiv$ there is a group of speakers $G$ such that members of $G$ are disposed to presuppose (by deploying a concept suitably connected to the name 'Alfred') that $x$ is an Alfred, because they believe that the other members of $G$ do the same.

It will be noted that this is essentially the claim that an individual is an Alfred if and only if there is a group of speakers in which there is a convention-in the sense of Lewis (1969) - to presuppose that he is. This is as it should be. What is characteristic of R-D properties like name-bearing, politeness, etc., is that they are embedded in, and have their distribution determined by, conventional social practices.

A few things to note about this approach. First, there will clearly be some slack in the proportion of the relevant group who must participate in the regularity (and the proportion which must be believed to participate in it). This is a familiar point from the literature on convention. Vagueness here seems appropriate given that there is plausibly vagueness in the distribution of the relevant properties. Second, the group within which there is a regularity must figure in the beliefs of the speakers about the regularity. Speakers must have beliefs about who they are coordinating their presuppositions with. ${ }^{25}$

25. A few caveats. First, it is possible, and presumably normal, for a speaker to take herself to be coordinating her presuppositions with a number of distinct groups, even with respect to the same referential target. Nothing in the characterization prevents that. Second, we will have to tolerate a substantial amount of non-overlap between different individuals' take on a group 
This is what explains why the initial mistake in the case of Madagascar doesn't automatically make it the case that the island bears the name. At that point there was no group which satisfied the condition specified in $\left(\mathrm{ALFRED}_{7}\right)$. There was a group which were disposed to presuppose that the island was a Madagascar (namely some group of Europeans); but they didn't do that because of beliefs about that group. They did it because of beliefs about a larger group containing the Africans from whom they took themselves to have learned the name. ${ }^{26}$ And there is a group which is such that beliefs about it guide the presuppositions of its members about the island's name. But that is a group in which the disposition to presuppose that the island is a Madagascar does not predominate. Again, this is general feature of convention-embedded $\mathrm{R}-\mathrm{D}$ properties not a peculiarity to name-bearing.

\subsection{Finks}

We should mention a general obstacle to giving R-D biconditionals in terms of dispositions. There are objects which intuitively bear R-D properties but which apparently fail to stand in the right relation to subjects' dispositions because they are specially situated with respect to the activating conditions for those dispositions. ${ }^{27}$ Johnston (1992) describes a shy chameleon. The chameleon is green but doesn't like to be seen. When it is placed in ideal lighting conditions it becomes embarrassed and turns red. This seems like a coherent description, but the R-D account of colours has trouble validating it. The chameleon is not disposed to look green in ideal conditions, it is disposed to look red (because it is disposed to change its colour). So the R-D account cannot countenance the fact that the chameleon is green when it is in non-ideal viewing conditions.

It's no surprise that we find similar cases with name-bearing. We can imagine cases in which although an individual bears a name, because of some special situation speakers are not willing to use the name in reference to the individual: the forbidden name of God, he who must not be named, etc. The R-D account of name-bearing cannot capture these situations, the worry goes, because they are cases in which an individual bears a name but speakers are not disposed to

in which they are both participating. We will have to allow that there is a group of the relevant sort when different members have a similar-enough take on it.

26. Of course we can imagine the case a different way. We could imagine that the Europeans had no interest in coordinating their presuppositions about the island's name with the Africans. They might have simply taken (their misconception of) the name used by the Africans as a handy suggestion for the inauguration of their own independent practice. If we imagine the case in this way, I take it that we are inclined to say that the island came to bear the name 'Madagascar' right away.

27. Garcia-Carpintero 2007 notes that one advantage of thinking about responsedependence in terms of a non-modal notion of essence is that finkish cases do not pose a special problem. 
presuppose that it does. ${ }^{28}$

So pursuing R-D approaches requires understanding how dispositions can be blocked by 'external' forces. An R-D approach must isolate some level of explanation at which the relevant disposition is grounded and hold that interference external to that level does not effect R-D properties (Johnston 1992. 231ff.). I won't offer a theory of how that goes here. We can assure ourselves that the relevant dispositions are present, even though masked, by considering relevant counterfactuals. Suppose that speakers in the relevant groups learned that relevant prohibitions had been lifted (he who must not be named has been defeated!). They would immediately be in a position to refer to him by name because their disposition to presuppose that he bears the relevant name would be un-masked.

\subsection{Baptism}

It would appear that the role that baptism-understood broadly so as to include the various ways that individuals can acquire names via stipulation-plays in name-bearing represents a disanalogy between name-bearing and other responsedependent properties. Objects cannot become red or tasty via stipulation. And in general, the relevance of stipulation to name-bearing appears to sit uncomfortably beside the thought that facts about name-bearing are determined by speakers' dispositions to presuppose.

First note that it isn't clear that resistance to stipulation is a general feature of R-D properties. With the right surrounding assumptions-i.e., with the right structures of deference-it seems possible to imagine a situation in which a particular person (say, Louis XIV) could stipulate that a certain action is polite thus making it the case that it was polite; or a particular person (say, Miles Davis) could stipulate that a certain person is cool. The situation with name-bearing is analogous.

To make this idea work, metalinguistic theorists should start with a simple picture of baptism: when a speaker attempts to baptize $o$ as $N$ they are avowing to presuppose that $o$ is an $N$. This sort of avowal gives other speakers a prima facie reason to do the same thing. Given the role that presuppositions play in communication, that one speaker presupposes that $P$ gives other speakers a reason to presuppose the same thing. This by itself gives us an initial picture of how a baptism might create a group of speakers who are disposed to presuppose that the baptized individual bears the stipulated name.

But this can only be part of the story. In the normal case, the group of speakers

28. Actually this isn't completely clear. In general, the presence of the licensing presupposition is consistent with speaker being unwilling to use a definite noun phrase for other reasons. We might presuppose in a context that Jones is the biggest jerk around, but still be unwilling to refer him with "the biggest jerk around" out of politeness. So R-D accounts of name-bearing could dig their heels in here instead. 
who take themselves to be coordinating about an individual's name will be a superset of the group of speakers who witness the individual's baptism. And if we want to hold that a baptism can (immediately) make it the case that an individual bears a name in such cases, we need to understand how a baptism can create the relevant dispositions in the larger group.

Note that it's easy to imagine name-using linguistic communities in which baptism plays no role (that is, in which there were no circumstances in which stipulations about names were determinative with respect to name-bearing). In communities of that kind, facts about name-bearing would be exclusively settled by the messy business of on-the-fly coordination of presuppositions. What distinguishes baptism-friendly name-using communities from baptism-unfriendly ones is the presence of dispositions to make one's name-presuppositions consistent with the avowals which are performed in certain canonical circumstances. Essentially, baptism-friendly name-using practices involve dispositions to defer in certain ways to certain privileged first-order dispositions to presuppose.

With this in view, baptism presents no obstacle to an R-D account of namebearing. That a baptism can make it the case that speakers in some broader group posses the relevant dispositions is partly explained by the presence of higher-order dispositions to defer in members of that group. That is, the group of speakers who is disposed to presuppose that $x$ is an Alfred might contain individuals who don't yet know his name but are disposed to presuppose that $x$ is an Alfred in virtue of being situated in a certain community and being disposed to modulate their dispositions to match dispositions which have a particular provenance. (For further discussion of the place of baptism in this kind of approach, see Gray 2014.)

\section{Circularity}

We'll take (ALFRED ${ }_{7}$ ) as on the right track as a non-reductive R-D account of name-bearing. It's time to face up to the possibility that an account of this kind is viciously circular. If it turns out to be, this would be a noteworthy result. If the argument above is correct, and metalinguistic theorists must conceive of name-bearing properties as response-dependent, and the best response-dependent approach is viciously circular, then metalinguistic theories must be abandoned. Metaphysics would trump linguistics.

As it happens, it's plausible that $\left(\mathrm{ALFRED}_{7}\right)$ is not viciously circular. The literature doesn't contain consensus on when a non-reductive R-D account is viciously circular. But I've articulated some relevant tests below. I'll argue that $\left(\mathrm{ALFRED}_{7}\right)$ passes them. 


\subsection{Contradiction}

The first test is whether the proposed account is contradictory or incoherent. To show that a proposed R-D account is not contradictory or incoherent we must reassure ourselves that it appeals, on the right-hand side, to a relation which it is possible for an object to stand in to a property. If it does, there is nothing contradictory about the proposal (cf. Boghossian \& Velleman 1989: 89). As an example of the danger here, it has been claimed that it is simply incoherent for an object to look to have a dispositional property (see the references in Cohen 2009 153). And if that is the case, this might be show that R-D accounts of colour are incoherent. But in the case of name-bearing, there is no analogous reason to worry. There is no reason to think that it isn't possible for an object $o$ and a property $P$ to be such that there is a group of speakers who are all disposed to presuppose that $o$ is $P$ because they believe that other members of the group are also so disposed.

\subsection{Triviality}

Another test for viciousness is whether the account is trivial. An obvious threat for non-reductive accounts is that the combination of employing the property one is characterizing in the biconditional, along with a characterization of ideal conditions which is too generous, will make the necessity of the biconditional a trivial affair. ${ }^{29}$ We learn nothing about the nature of squareness by learning that it is a necessary truth that $x$ is square if and only subjects are disposed to judge that it is square under conditions in which they are infallible about squareness.

To test for triviality, we can substitute some other kind of property in $\left(\mathrm{ALFRED}_{7}\right)$ and see whether it remains a necessary truth. Here we test with squareness:

SQUARE $x$ is square $\equiv$ there is a group of speakers $G$ such that members of $G$ presuppose (by deploying a concept suitably connected to the adjective 'square') that $x$ is square, because they believe that the other members of $G$ do the same.

(SQUARE) is not a necessary truth; that a group of speakers all presuppose that some object is a square is consistent with its not being one. It would be an unusual situation. But the fact that speakers coordinate their presuppositions about the shape of a given object does not mean that what they presuppose is true. They could all be mistaken. As metalinguistic theorists would put it, calling something a square doesn't make it one. Calling someone Alfred makes him one..$^{30}$ So our

29. See McGinn (1983 6), Johnston (1989 147;1992 230), Wright (1989 247ff.), Peacocke 1992 35).

30. Just to avoid confusion: this claim is independent of the nebulous, though perhaps truistic, idea that meaning is determined by use. I don't deny that if speakers systematically 
R-D account of name-bearing is not trivial.

A clarification: the claim isn't that the right-hand side of (SQUARE) doesn't characterize any property. We can happily admit that the right-hand side characterizes a genuine condition that an object might satisfy, and so it characterizes a property. ${ }^{31}$ The claim is simply that the property it characterizes is not necessarily co-extensive with the property square. More broadly, the point is that the schema you get by removing the occurrences of 'Alfred' in $\left(\mathrm{ALFRED}_{7}\right)$ is not such that it holds of an arbitrary property. Some properties are not response-dependent in this way. That is enough to show that the analysis is not trivial.

\subsection{Regress}

A more tricky kind of potential viciousness involves the possibility of a regress. This kind of worry has always dogged non-reductive response-dependent accounts (see Boghossian \& Velleman 1989: Byrne \& Hilbert 2011; Cohen 2009: 166 and the references there). The details of how it might go depend on the kind of R-D account on offer. The objection deploys a substitution of the proposed R-D analysis within itself. So, for example, if we claim that being red is being disposed to look red, we can substitute 'being disposed to look red' wherever we find 'red'. This, the objection goes, entails that being red is being disposed to look disposed to look red. And 'red' occurs again here, so we can substitute again, etc. The regress is supposed to show that the R-D account entails that colours have infinitely different appearances, or perhaps no fixed appearance, or some other untoward consequence.

First note that, strictly, the objection requires that we treat the R-D account as an identity, rather than simply as a necessary biconditional. And all we have been doing so far as it treating it as a necessary biconditional. But it would be unsatisfying to rest a defense of the R-D account on the controversial distinction between necessarily coextensive properties. So we'll ignore this.

One response available to some R-D accounts-see McGinn (1983: 133), Cohen (2009 170), and Byrne and Hilbert (2011) Section 2)-is to note that the R-D property occurs in a hyper-intensional context on the right hand side of the R-D biconditional (for example, in the scope of 'looks'). Substitution of identicals is not truth-preserving in this context and so the proposed regress does not begin.

used the sign 'square' differently, it would be true of different things. This is consistent with the point at issue here, which revolves only around what would happen if speakers presupposed that some particular object is square.

31. We might even admit that it characterizes a property that is sometimes expressed by occurrences of 'square'. Perhaps in special contexts-involving speakers who are ignorant of what 'square' means-occurrences of 'square' express this property. I'm sceptical of this. But even if it is true, the point about triviality still stands. Thanks to an editor and referee for helpful comments here. 
But we cannot offer this response. Recall that we are treating 'Alfred' as occurring in a transparent position on the right-hand side of $\left(\mathrm{ALFRED}_{7}\right)$. So we must accept that the relevant substitutions are legitimate. So, for example, we must accept that $\left(\mathrm{ALFRED}_{7}\right)$ entails $\left(\mathrm{ALFRED}_{7+}\right)$

ALFRED $_{7+} x$ is an Alfred $\equiv$ there is a group of speakers $G$ such that members of $G$ are disposed to presuppose (by deploying a concept suitably connected to the name 'Alfred') that $x$ is [such that there is a group of speakers $H$ such that members of $H$ are disposed to presuppose (by deploying a concept suitably connected to the name 'Alfred') that $x$ is an Alfred, because they believe that the other members of $H$ do the same], because they believe that the other members of $G$ do the same.

This is certainly cumbersome (I've added brackets to show where the substitution has occurred). And, of course, the substitution could be performed again (I'll spare readers the demonstration). But is it worrying?

Byrne and Hilbert 2011: 345) note that if the R-D property occurs in a transparent position then the regress of substitutions is innocuous. If it occurs in a transparent position, then it functions semantically simply to pick out which property is the object of subjects' responses. Thus the different ways of picking out that property which correspond to the different substitution iterations do not make different claims about the relevant subjects. The various iterations do not require that subjects have different dispositions. They are merely different ways of describing the same dispositions (compare: the disposition to believe of Superman that he is $F=$ the disposition to believe of Clark Kent that is he $F$ ).

\subsection{Non Well-Foundedness ${ }^{32}$}

There is another worry, related to the previous one, but more difficult to formulate precisely. I'm going to call it the problem of non well-foundedness. Consider again the sequence of substitution iterations we introduced a moment ago: $\left(\mathrm{ALFRED}_{7}\right)$, $\left(\mathrm{ALFRED}_{7+}\right),\left(\mathrm{ALFRED}_{7++}\right)$, etc. At each stage, the distribution of the property of being an Alfred is characterized in terms of (more deeply embedded) occurrence of that property. We will never reach a stage at which we characterize the distribution in some other terms.

On the one hand, this shouldn't be a surprise. In giving a non-reductive R-D biconditional, we are acknowledging that we cannot characterize the distribution of a name-bearing property in terms which don't involve that property. But we still might worry that there is something incomplete about an account of this kind. One way to see this is to think about the individuation-conditions for non-reductively characterized R-D properties.

32. Thanks to Dave Hilbert for discussion here and to an anonymous reviewer for pointing to the material in Lewis. 
Suppose we had a complete non-reductive R-D theory of the colours (that is, we knew that each colour satisfied some schema of the form: $x$ is ... iff $x$ is disposed to look ... in conditions C). We couldn't learn from that theory whether red and green were different colours. Or, for that matter, whether it was possible for any two objects to differ in colour. The total R-D colour theory would entail that colours $X$ and $Y$ differ in distribution if and only if there is an object which is disposed to look X but not disposed to look Y. But the R-D biconditional won't tell you anything about whether being disposed to look red is being disposed to look blue is being disposed to look yellow, etc. (Lewis 1997). If one already knew that, one could see that the relevant dispositions were distinct. If one didn't already know that, learning that colours satisfied the relevant schemas wouldn't tell you whether the dispositions are distinct.

We don't want to overstate this worry. In giving a non-reductive R-D biconditional we are aiming to characterize, in an illuminating way, how a property relates to subjects' responses. We are not characterizing everything that is true about the nature of the R-D property. So it's perfectly possible that to understand the identity and difference of response-dependent properties we need to look beyond R-D biconditionals.

But the situation is puzzling. Non-reductive R-D biconditionals characterize a reflexive structure which is, in some sense, incomplete on its own. The responsedependent form of these properties must be filled out by something else. This might be a kind of non-response dependent substrate of the response-dependent property: an additional feature of its essence. In the case of colours, this might be something like the phenomenology of experience of the colour (Lewis 1997: Section VII). Or it might something like a non-response dependent accretion: an accidental truth about the property. In the case of colour, this might be something like: facts about what objects are commonly known to have which colours (fire-engines are red, the sky is blue, etc.) (Lewis 1997. Section V).

As it happens, we have already said enough about name-bearing properties to give an outline of an answer. In the case of name-bearing the substrate is linguistic. For the metalinguistic theorist, name-bearing properties are essentially connected to the names which have them as part of their meaning. We have already seen this from a different angle when we showed that the sorts of presuppositions which are extension-determining for name-bearing properties require that speakers think of those properties in a way that is connected to names qua linguistic expressions. Given that $\left(\mathrm{ALFRED}_{7}\right)$ makes reference to the expression 'Alfred', the features of that expression which exceed its connection to the property of being an Alfred constitute reductive elements of $\left(\mathrm{ALFRED}_{7}\right)$. In the sequence of iterations of $\left(\mathrm{ALFRED}_{7}\right)$, one thing that will remain constant is reference to the expression 'Alfred'. Thus the expression itself will act as a non-response dependent anchor for the response-dependent characterization of the property. 
In particular, features of the expression which are independent of its meaningfor example its orthography and phonology-will distinguish being an Alfred from being a Peter, etc. Thus facts about the identity and distinctness of namebearing properties will be grounded in facts about the identity and distinctness of linguistic expressions (for a discussion of the difficulties of a simple version of this idea, see Gray 2015).

\section{An Application of the Account}

I'll finish by showing how an R-D account of name-bearing can do important explanatory work for metalinguistic theories. I'll show that the form of interdependence we have posited between name-bearing and presupposition illuminates features of a name-using practice which would otherwise be puzzling from the point of view of metalinguisticism.

First, recall a general feature of metalinguisticism: these approaches hold that reference with a name has a descriptive element. What is characteristic of these approaches is that the reference of an occurrence of a name is semantically constrained by the corresponding name-bearing property. This is in contrast to traditional homonymist approaches, which treat names as individual constants.

Note that this is descriptive constraint on reference not descriptive determination of reference. Metalinguistic theorists posit a non-descriptive component of reference-fixation, and so don't run afoul of Kripke's attacks on descriptivism about reference (see Gray 2014). But there is a different, unnoticed, worry in this vicinity. Even descriptive constraint potentially interferes with an important discourse function of proper names.

What's the point of having names in a language? Why couldn't we get by with other referential devices (pronouns, demonstratives, definite descriptions, etc.)? The answer is multifaceted, but one thought is that names, and an associated set of normative name-using practices, facilitate communication about individuals by bypassing the need for speakers to coordinate their descriptive knowledge of referential targets. Here is Evans (for variations on the same theme see Searle 1958. 172 and Strawson 1974 38):

[In a community of speakers] there will not be a naturally arising overlap between the information possessed by different people, adequate to ensure that any pair of people who possess information from an individual, and who can profitably engage in discussion and exchange of information, will be able to do so using a description .... The institution of bestowing a name on someone-thereby producing an arbitrary distinguishing feature which everyone learns-certainly lessens the difficulty of achieving referential communication. (Evans 1982 ; 379) 
The idea is that in many contexts in which speakers have a reason to communicate about an individual, that individual will not be identifiable by means immediately available to speakers in virtue of their being situated in the context (i.e., the target may not be perceptible, previously mentioned, etc.). Without names, speakers would have to rely on devices that required them to coordinate their descriptive information about the referential target. But in many normal cases, speakers who have a reason to communicate about the same individual will not have coordinated information of the right sort. Names, and the linguistic norms associated with them, serve to facilitate communication in situations like this.

There are two components to Evans's idea: $i)$ that names are 'arbitrary distinguishing features'; ii) that there is a norm that everyone learn the name of individuals about whom they have a need to communicate. The arbitrariness of names is important because it allows speakers to distribute names over referential targets such that an individual's name tends to distinguish them from other likely referential targets in contexts where they are salient. The name-learning norms are important because if an individual's name was not widely known in a group of speakers, it couldn't serve as the basis for communication in arbitrary contexts in which speakers know little about each other's relation to the referential target. For the system to function, individual speakers must be able, simply by paying attention to how an individual is referred to in particular contexts, to learn a device which is generally suitable for communication about the individual in a wider group.

There is an apparent tension between this idea and metalinguistic approaches to names. Metalinguistic approaches treat names as partially-descriptive devices of reference and Evans's idea is that the discourse function of names is premised on their being non-descriptive. I'll suggest that metalinguistic approaches are consistent with Evans's idea, but only given the kind of R-D account of names developed above.

To see this, we can distinguish two senses in which an assignment of features to a class of objects might be arbitrary. Let's say an assignment is stipulatively arbitrary if agents can determine how those features are distributed over objects and that determination is relatively unconstrained by antecedent features of the objects. The idea is that agents determine the distribution of some set of properties and that establishing one distribution would require no more or less work than establishing another. An example: everyone at a party needs to be given a party hat, but it doesn't matter who gets which hat. I'm free to distribute the hats how I choose, and no distribution is easier to achieve than any other.

Let's say that an assignment of features is dynamically arbitrary if the distribution is stipulatively arbitrary and it cannot systematically diverge from subjects' take on it. If a distribution of features is dynamically arbitrary then nothing outside subjects' take on those features constrain their distribution. If subjects' 
take on the features changes, the features change to match the new take.

In the context of metalinguistic theories, the discourse function that Evans posits for names requires that name-bearing is dynamically arbitrary ( 'requires' might be too strong; perhaps 'strongly prefers' is better). Suppose that namebearing is only stipulatively arbitrary. This is essentially how name-bearing is treated by the dubbing approach (discussed in Section 3.1). On that approach, names can be distributed via baptism; and (within certain limits, and abstracting from cultural restrictions) any distribution of names is as easy to achieve as any other. But on this model names are not dynamically arbitrary; speakers can have false beliefs about who was baptised with which name. And so their take on the distribution of name-bearing properties can diverge from the actual distribution.

On this supposition, the norms associated with a name-using practice are potentially in conflict with the norms of truth which govern discourse in general. Recall that the name-using norms require that I learn and use the names for objects which are commonly in use in my speech-community. But there is no guarantee, if names are only stipulatively arbitrary, that the names that are commonly used will actually be born by the relevant individuals. One could discover that the names that were in common use didn't match the baptisms. In this case, one would have to choose between the norms of name-use and the norm of truth. And more serious than actual situations of divergence (which might, after all, be rare), the possibility of conflict would interfere with the smooth coordination of expectations which a name-using practice requires.

The R-D account of name-bearing developed above entails that name-bearing is dynamically arbitrary. The distribution of name-bearing properties is determined by speakers' presuppositions about them. Even though names are partially-descriptive devices of reference, they are perfectly suited to playing Evans's discourse function because the distribution of the properties which constrain individual acts of reference is determined by general patterns of reference. This is precisely the structure we would want if we were to design a partially descriptive device to play a role in a name-using practice. ${ }^{33}$

This is just a sketch of how the metalinguistic approach to names, the structure of name-using practices, and the metaphysics of name-bearing interact. ${ }^{34}$ It's $^{\prime}$

33. Note that this is not an argument that non-descriptive, homonymist approaches cannot explain how names play the Evans discourse role. That would depend on the sort of metasemantics one adopts in that framework. In fact, I encourage homonymists to take the kind of response-dependent account I have outlined here, and with appropriate modifications, take it as their metasemantics for names.

34. Reflection on the structure of name-using practices might, in turn, guide us in developing the R-D account of name-bearing. The role that names play in distinguishing potential referential targets may, for example, lead us to think of name-responses in a holistic rather than an atomistic way. Instead of thinking of each disposition to presuppose individually, perhaps the fundamental thing is a speaker's disposition to deploy a class of name-bearing 
enough, I hope, to show how the non-reductive R-D account of name-bearing might earn its keep by illuminating a feature of names which would otherwise be puzzling for the metalinguistic theorist.

\section{Conclusion}

The linguistic debate between homonymists and metalinguisticists about names is entangled with a metaphysical question about the nature of name-bearing. From the perspective of metalinguistic approaches, name-bearing ought to be treated as a kind of response-dependent property. And the prospects for a reductive response-dependent account of name-bearing are not good. We can develop a non-reductive response-dependent account of name-bearing by treating the distribution of name-bearing properties as determined by the dispositions to form presuppositions about name-bearing properties in groups of speakers. An account of this kind has the potential to illuminate how the nature of name-bearing properties interacts with the function of a name-using practice.

\section{Acknowledgments}

This is the descendant of an unpublished paper called "Name-Bearing, ResponseDependence and Arbitrariness". It is also, in a sense, a sequel to Gray (2014). I have benefited from discussions with an audience at the conference on names, expressives, and demonstratives in Gargnano in 2014, and an audience at the Institut Jean Nicod in 2017. I have also benefited from discussion with Zed Adams, Manuel Garcia-Carpintero, Rachel Goodman, John Hawthorne, Dave Hilbert, Robin Jeshion, and Francois Recanati, and from the comments of two anonymous reviewers and the editor.

\section{References}

Bach, Kent (2002). Giorgione Was So-Called Because of His Name. Philosophical Perspectives, 16, 73-103.

Bach, Kent (2015). The Predicate View of Proper Names. Philosophy Compass, 10(11), 772-784.

Blackburn, Simon (1993). Circles, Finks, Smells and Biconditionals. Philosophical Perspectives, 7, 259-279.

Boghossian, Paul A. and J. David Velleman (1989). Colour as a Secondary Quality.

properties to draw distinctions amongst a class of potential referential targets. This sort of holistic conception of a class of R-D properties also has precedent in the literature; Hume, for example, seemed to think of judgments of taste as irreducibly contrastive. 
Mind, 98(389), 81-103.

Brynjarsdóttir, Eyja M (2008). Response-Dependence of Concepts Is Not for Properties. American Philosophical Quarterly, 45(4), 377-386.

Burge, Tyler (1973). Reference and Proper Names. Journal of Philosophy, 70(14), 425439.

Byrne, Alex and David R. Hilbert (2011). Are Colours Secondary Qualities? In

L. Nolan (Ed.), Primary and Secondary Qualities (349-361). Oxford University Press.

Cohen, Jonathan (2009). The Red and the Real: An Essay on Color Ontology. Oxford University Press.

Delgado, Laura (2016). Between Singularity and Generality: The Semantic Life of Proper Names. Manuscript in preparation.

Elbourne, Paul (2005). Situations and Individuals. MIT Press.

Evans, Gareth (1982). The Varieties of Reference. John McDowell (Ed.). Clarendon Press.

Evans, Gareth (1985). The Causal Theory of Names. In Collected Papers (1-24). Oxford University Press.

Fara, Delia Graff (2015). Names are Predicates. Philosophical Review, 124(1), 59-117. García-Carpintero, Manuel (2007). A Non-Modal Conception of Secondary Properties. Philosophical Papers, 36(1), 1-33.

Garcia-Carpintero, Manuel (in press). The Mill-Frege Theory of Proper Names. Mind.

Geurts, Bart (1997). Good News about the Descriptions Theory of Names. Journal of Semantics, 14(4), 319-348.

Glanzberg, Michael (2014). Explanation and Partiality in Semantic Theory. In Alexis Burgess and Brett Sherman (Eds.), Metasemantics: New Essays on the Foundations of Meaning (259-292). Oxford University Press.

Gray, Aidan (2012). Names and Name-Bearing: An Essay on the Predicate View of Names (Unpublished doctoral dissertation). University of Chicago.

Gray, Aidan (2014). Name-Bearing, Reference, and Circularity. Philosophical Studies, $171(2)$, 207-231.

Gray, Aidan (2015). Lexical Individuation and Predicativism about Names. Thought: A Journal of Philosophy, 4(2), 113-123.

Gray, Aidan (2017a). Lexical-Rule Predicativism about Names. Synthese. Advance online publication. doi:10.1007/s11229-017-1462-4

Gray, Aidan (2017b). Names in Strange Places. Linguistics and Philosophy. Advance online publication. doi:10.1007/s10988-017-9205-z

Heim, Irene and Angelika Kratzer (1998). Semantics in Generative Grammar. Blackwell.

Holton, Richard (1991). Intentions, Response-Dependence, and Immunity from Error. In P. Menzies (Ed.), Response Dependent Concepts (83-121). 
Hornsby, Jennifer (1976). Proper Names: A Defence of Burge. Philosophical Studies, $30(4), 227-234$.

Howat, Andrew William (2011). Shallow versus Deep Response-Dependence. Philosophical Studies, 156(2), 155-172.

Johnston, Mark (1989). Dispositional Theories of Value. Proceedings of the Aristotelian Society, Supplementary Volumes, 63, 139-174.

Johnston, Mark (1992). How to Speak of the Colors. Philosophical Studies, 68(3), 221263.

Johnston, Mark (1993). Objectivity Refigured: Pragmatism without Verificationism. In John Haldane and Crispin Wright (Eds.), Reality: Representation and Projection (85-130). Oxford University Press.

Kaplan, David (1990). Words. Proceedings of the Aristotelian Society, 64, 93-119.

Katz, Jerrold J. (1990). Has the Description Theory of Names Been Refuted? In George Boolos (Ed.), Meaning and Method: Essays in Honor of Hilary Putnam. (31-61). Cambridge University Press.

Kripke, Saul (1980). Naming and Necessity. Harvard University Press.

Lebar, Mark (2005). Three Dogmas of Response-Dependence. Philosophical Studies, 123(3), 175-211.

Lewis, David (1969). Convention: A Philosophical Study. Harvard University Press.

Lewis, David (1989). Dispositional Theories of Value. Proceedings of the Aristotelian Society, Supplementary Volumes, 63, 113-137.

Lewis, David (1997). Naming the Colours. Australasian Journal of Philosophy, 75(3), 325-342.

Loar, Brian (1976). The Semantics of Singular Terms. Philosophical Studies, 3o(6), 353-377.

Loar, Brian (1980). Names and Descriptions: A Reply to Michael Devitt. Philosophical Studies, 38(1), 85-89.

Maier, Emar (2009). Proper Names and Indexicals Trigger Rigid Presuppositions. Journal of Semantics, 26(3), 253-315.

Matushansky, Ora (2006). Why Rose is the Rose: On the Use of Definite Articles in Proper Names. In O. Bonami and P. Cabredo Hofherr (Eds.), Empirical Issues in Syntax and Semantics 6 (285-307).

Matushansky, Ora (2008). On the Linguistic Complexity of Proper Names. Linguistics and Philosophy, 31(5), 573-627.

McDowell, John (1985). Values and Secondary Qualities. In Ted Honderich (Ed.), Morailty and Objectivity (110-129). Routledge \& Kegan Paul.

McDowell, John (1987). Projection and Truth in Ethics. University of Kansas, Department of Philosophy.

McGinn, Colin (1983). The Subjective View: Secondary Qualities and Indexical Thoughts. Cambridge University Press.

McGinn, Colin (1996). Another Look at Color. The Journal of Philosophy, 93(11), 537- 
553.

Peacocke, Christopher (1984). Colour Concepts and Colour Experience. Synthese, 58(3), 365-381.

Peacocke, Christopher (1992). A Study of Concepts. MIT Press.

Pelczar, M. and J. Rainsbury (1998). The Indexical Character of Names. Synthese, 114(2), 293-317.

Pettit, Philip (1991). Realism and Response-Dependence. Mind, 100(4), 587-626.

Rami, Dolf (2014a). On the Unification Argument for the Predicate View on Proper

Names. Synthese, 191(5), 841-862.

Rami, Dolf (2014b). The Use-Conditional Indexical Conception of Proper Names. Philosophical Studies, 168(1), 119-150.

Recanati, Francois (1997). Direct Reference: From Language to Thought. Blackwell.

Sawyer, Sarah (2009). The Modified Predicate Theory of Proper Names. In

Sarah Sawyer (Ed.), New Waves in Philosophy of Language (206-225). Palgrave MacMillan Press.

Schoubye, Anders J. (2016a). The Predicative Predicament. Philosophy and Phenomenological Research. Advance online publication. doi:10.1111/phpr.12336

Schoubye, Anders J. (2016b). Type Ambiguous Names. Mind. Advance online publication. doi:10.1093/mind/fzvi88

Searle, John R. (1958). Proper Names. Mind, 67(266), 166-173.

Sloat, Clarence (1969). Proper Nouns in English. Language, 45(1), 26-30.

Stalnaker, Robert C. (1974). Pragmatic Presupposition. In M. Munitz and P. Under (Eds.), Semantics and Philosophy (197-213). New York University Press.

Stalnaker, Robert C. (1978). Assertion. In P. Cole (Ed.), Syntax and Semantics, Volume 9: Pragmatics (315-332). Academic Press.

Strawson, Peter (1974). Subject and Predicate in Logic and Grammar. Ashgate.

Sveinsdóttir, Ásta Kristjana (2008). Siding with Euthyphro. European Journal of Philosophy, 18(1), 108-125.

Tolonen, Mikko (2008). Politeness, Paris and the Treatise. Hume Studies, 34(1), 2142.

Watkins, Michael (1994). Dispositionalism, Ostension, and Austerity. Philosophical Studies, 73(1), 55-86.

Wedgwood, Ralph (1998). The Essence of Response-Dependence. In Roberto Casati and Christine Tappolet (Eds.), European Review of Philosophy, 3: ResponseDependence (31-54). CSLI Publications.

Wright, Crispin (1988). The Inaugural Address: Moral Values, Projection and Secondary Qualities. Proceedings of the Aristotelian Society, Supplementary Volumes, 62, 1-26.

Wright, Crispin (1989). Wittgenstein's Rule-Following Considerations and the Central Project of Theoretical Linguistics. In A. George (Ed.), Reflections on Chomsky (233-264). Blackwell. 